\title{
La salud reproductiva de los y las jóvenes de áreas rurales
}

Population Council

Follow this and additional works at: https://knowledgecommons.popcouncil.org/departments_sbsr-rh How does access to this work benefit you? Let us know!

\section{Recommended Citation}

"La salud reproductiva de los y las jóvenes de áreas rurales," Información Jóvenes México. Mexico City: Population Council, 2005. 


\section{la salud reproductiva de los y las jóvenes de áreas rurales}
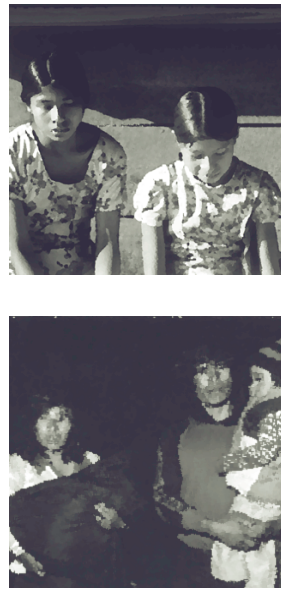

La salud reproductiva de los y las jóvenes es una cuestión global de derechos humanos porque, más allá del individuo, tiene un impacto sobre la familia, la sociedad, la economía y la comunidad global.

\section{Referencias}

1. CONAPO, 11 de Julio Día Mundial de la Población. 2004, Consejo Nacional de Población: México. p. 13.

2. Artículo $4^{\circ}$ de la Constitución Política de los Estados Unidos Mexicanos.

3. CONAPO, Serie Documentos Técnicos: Situación actual de las y los jóvenes en México. Diagnóstico sociodemográfico, 2000, Consejo Nacional de Población: México. p. 27, 56, 60, 62

4. SSA, Programa de Acción: Programa de atención a la salud de la adolescencia. 2002, Secretaría de Salud, Subsecretaría de Prevención y Protección de la Salud: México. p. 27

5. CONAPO, Consejo Nacional de Población. 2003

6. IMSS, Diagnóstico Cualitativo para la Elaboración de un Programa de Salud Reproductiva en Adolescentes de Áreas Rurales. 1999, Instituto Mexicano del Seguro Social: México.

7. Demysex y CNDH, Cartilla de los Derechos Sexuales de las y los Jóvenes. 2003, Comisión Nacional de los Derechos Humanos, Red Democracia y Sexualidad, Campaña Nacional por los Derechos Sexuales de las y los Jóvenes: Hagamos un Hecho Nuestros Derechos.

8. Naciones Unidas. Programa de Acción de la Conferencia Internacional sobre Población y Desarrollo, en Conferencia Internacional sobre Población y Desarrollo. 1994. Cairo, Egipto.

9. Declaración de los Derechos Sexuales de las y los Jóvenes. En: Foro Nacional de Jóvenes por los Derechos Sexuales. 2000. Tlaxcala, México: Instituto Mexicano de la Juventud, Dirección de Programas para la Juventud del Gobierno del Distrito Federal.
Los y las jóvenes tienen derecho a estos recursos, los cuales son garantizados por varios acuerdos nacionales e internacionales y por la Constitución de los Estados Unidos Mexicanos:

- “... El personal de los servicios de salud pública no debe, bajo ninguna condición, negarme información o atención y éstas no deben estar sometidas a ningún prejuicio." —Cartilla de los Derechos Sexuales de los y las Jóvenes, desarrollado durante la Campaña Nacional por los Derechos Sexuales de las y los Jóvenes: Hagamos un Hecho Nuestros Derechos, México, 2003 [7].

“...Como parte del esfuerzo encaminado a satisfacer las necesidades no atendidas, se pide a todos los países que determinen y eliminen todas las barreras importantes que todavía existen para la utilización de los servicios de planificación de la familia." - Programa de Acción de la Conferencia Internacional de Población y Desarrollo, Cairo, Egipto, 1994 (del cual México es un signatario) [8].

¿Cuales son las barreras que impiden que en las áreas rurales las y los jóvenes acudan a los servicios de salud a los que tienen derecho?

Los y las jóvenes no saben que existen los servicios, no confían en los proveedores o temen que haya una falta de confidencialidad al momento de prestarse el servicio [6]. Estas barreras evitan que ellos y ellas acudan a las clínicas para obtener información y servicios de salud reproductiva. Los proveedores de salud sienten que no tienen la capacitación o actualización necesarias en temas de sexualidad y metodología anticonceptiva [6]. Estos proveedores deben estar mejor preparados e informados para satisfacer las necesidades de los y las jóvenes.

- La virginidad es especialmente valorada en las comunidades rurales; los padres pueden, incluso, llegar a rechazar a una hija que haya tenido relaciones sexuales antes del matrimonio [6]. En esta cultura, las mexicanas de áreas rurales no se atreven a acudir a servicios de salud reproductiva por temor a ser rechazadas por sus familias y sus comunidades.

El gobierno mexicano debe encargarse de mejorar el acceso a los servicios de los y las jóvenes y la capacitación de los proveedores que les atienden, de acuerdo con los derechos establecidos en la Declaración de los derechos de los jóvenes mexicanos desarrollada por 78 organizaciones que participaron en el Foro Nacional de Jóvenes por los Derechos Sexuales, realizado en Tlaxcala, México, en 2000:

a...Recibir información y atención por personal sensible, respetuoso y capacitado en los temas. Conocer, tener acceso e información para el uso adecuado de toda la gama de métodos anticonceptivos y alternativas para la prevención de infecciones de transmisión sexual, VIH, embarazos no planeados o no deseados." -Declaración de los derechos de los jóvenes mexicanos, desarrollada por 78 organizaciones que participaron en el Foro Nacional de Jóvenes por los Derechos Sexuales realizado en Tlaxcala, México, 2000 [9].

Por otra parte, en áreas rurales las mujeres son más valoradas cuando tienen hijos, por lo cual es más común que usen métodos anticonceptivos para espaciar los hijos que para retrasar el primer embarazo [6]. Dentro de esta cultura, no es común que una mujer joven use métodos anticonceptivos para evitar un embarazo. Los hombres, lo mismo que las mujeres, tienen el derecho a planear sus familias como mejor les convenga:

"Como mujer u hombre joven tengo derecho a decidir, de acuerdo con mis deseos y necesidades, tener o no tener hijos, cuántos, cuando y con quién. El Estado debe respetar y apoyar mis decisiones sobre mi vida reproductiva, brindándome la información y los servicios de salud que requiero, haciendo efectivo mi derecho a la confidencialidad." - Cartilla de los Derechos Sexuales de los y las Jóvenes, desarrollado durante la Campaña Nacional por los Derechos Sexuales de las y los Jóvenes: Hagamos un Hecho Nuestros Derechos, México, 2003 [7].

Para asegurar a las y los jóvenes el pleno ejercicio de sus derechos reproductivos, se recomienda:

- Proveer a la gente joven de áreas rurales una educación que les brinde información sobre sus derechos y los servicios de salud reproductiva, respetando siempre su cultura tradicional.

Asegurar suficiente abasto de productos y servicios de planificación familiar en las áreas rurales. Mantener un adecuado nivel de capacitación de los proveedores de salud de áreas rurales, incluyendo la provisión de educación continua, para que estén actualizados sobre las nuevas tecnologías anticonceptivas. Prestar atención especial a los estados cuyas carencias son más evidentes, como Chiapas, Guanajuato, Michoacán y Oaxaca. 